
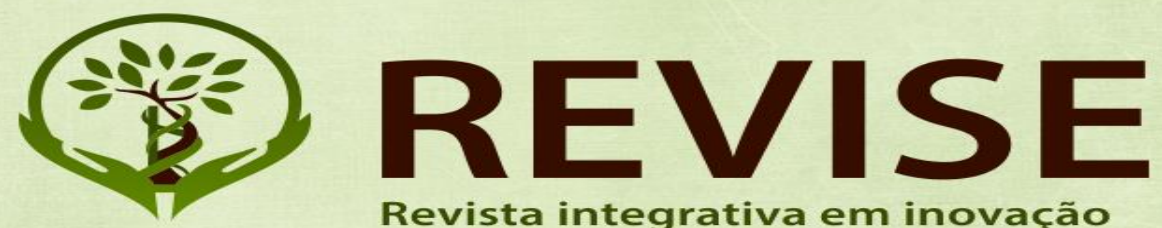

Revista integrativa em inovação tecnológica nas ciências da saúde

\title{
Minicurso: ECONOMIA CRIATIVA E SUSTENTABILIDADE
}

Sonia Maria Dalcomuni

UFES

\section{RESUMO}

O artigo registra os cursos do congresso internacional de inovação tecnológica nas ciências da saúde: a sustentabilidade das práticas integrativas a agroecologia, mais especificamente o minicurso Economia Criativa E Sustentabilidade. O minicurso apontou a economia criativa como um dos elementos das Tecnologias da Informação e Comunicação - TIC's: criatividade, desenvolvimento econômico, ciência \& tecnologia - C\&T e redes de cooperação. O evento aconteceu de 15 a 18 de novembro de 2017 no IFBA SAJ sob a direção da Universidade Federal do Recôncavo da Bahia.

Palavras-chave: Criatividade. Redes de cooperação. Desenvolvimento Econômico. C\&T.

\begin{abstract}
The article registers the courses of the international congress on technological innovation in health sciences: the sustainability of integrative practices in agroecology, more specifically the short course Creative Economy and Sustainability. The short course pointed to the creative economy as one of the elements of Information and Communication Technologies - ICTs: creativity, economic development, science \& technology - C \& T and cooperation networks. The event took place from November 15 to 18,2017 at IFBA SAJ under the direction of the Federal University of Recôncavo da Bahia.
\end{abstract}

Keywords: Creativity. Cooperation networks. Economic development. S\&T. 

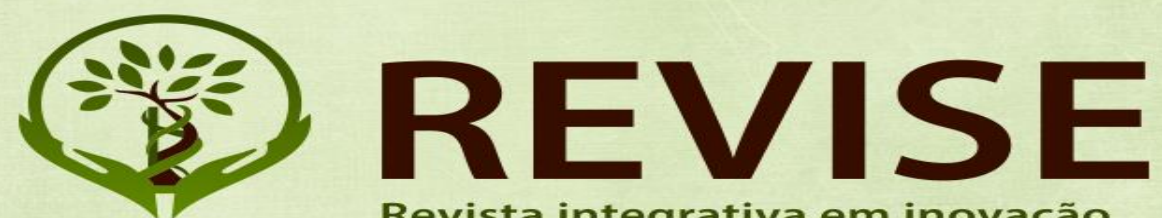

Revista integrativa em inovação tecnológica nas ciências da saúde

ISSN: $2179-6572$

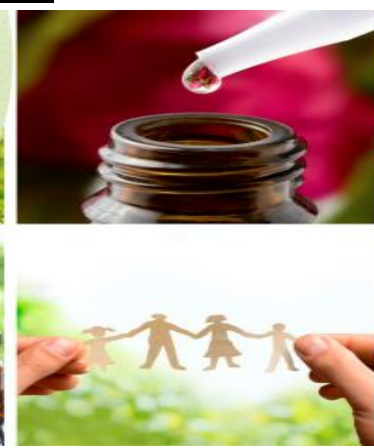

A economia criativa diz respeito a criatividade, conhecimento e sustentabilidade. Parte da economia da escassez para a economia da abundância, como vetor do desenvolvimento sustentável. A importância da economia criativa diz respeito a evolução tecnológica, portanto ao paradigma das TIC's que se compõem dos elementos de desafios contemporâneos, criatividade, ciência \& tecnologia, desenvolvimento econômico e redes de cooperação. O ambientalismo, um dos focos da evolução tecnológica é o paradigma institucional da sustentabilidade que integra os princípios da vida com qualidade no contexto de uma economia fechada, planeta finito, economia ecológica.

O desenvolvimento sustentável é o desenvolvimento que atende as necessidades do presente sem comprometer a capacidade das gerações futuras atenderem às próprias necessidades. A sustentabilidade possui as dimensões socioeconômicas da saúde e educação; política/cultural do respeito à diversidade;geográfica com a distribuição mais equitativa das atividades humanas. Assim, o produto nacional pode ser indicado como resultado do capital, trabalho e mudança técnica agroecológica com pesquisa científica, aperfeiçoamento dos processos industriais, melhorias gerenciais, fluxos de informação mais eficientes nas empresas, melhor qualidade da educação e no treinamento da força de trabalho. (Solow, 1957) A riqueza social (G) poderá com o desenvolvimento sustentável ser composta pela renda nacional social (Y), a qualidade do meio ambiente (E), que são elementos importantes da combinação do trabalho (L), capital (K), natureza (N) e mudança técnica (A). 